\title{
Astrobiology as Hybrid Science: Introduction to the Thematic Issue
}

\author{
Linnda R. Caporael ${ }^{1,2}$
}

Published online: 4 April 2018

(c) Konrad Lorenz Institute for Evolution and Cognition Research 2018

In all societies, people have constructed myths about the origins of the universe and of humans. The function of these myths is to define our place in nature and thus to give us a sense of purpose and value. Since Darwinism is, among other things, an account of human origins, is it any wonder that it is expected to carry a moral message?

Maynard Smith, 1984

1.1. ... Astrobiological research potentially has much broader consequences than simply scientific discovery, as it includes questions that have been of great interest to human beings for millennia (e.g., are we alone?) and raises issues that could affect the way the human race views and conducts itself as a species (e.g., what are our ethical responsibilities to any life discovered beyond Earth?).

1.2. Have we already found life beyond Earth? No.

$$
\text { “The Astrobiology Primer v2.0" (2016) }
$$

"Astrobiology is the study of the origin, evolution, distribution, and future of life in the universe" (https:// astrobiology.nasa.gov/about/). One struggles to figure out exactly what, if anything, this statement excludes. I came to writing this article by way of an invitation to participate in the multidisciplinary "Blumberg Dialogues," sponsored by

Linnda R. Caporael

linnda.caporael@gmail.com

1 Cognitive Science Program, Indiana University, Bloomington, IN, USA

2 Professor Emerita, Department of Science and Technology Studies, Rensselaer Polytechnic Institute, Troy, NY, USA the US Library of Congress and National Aeronautics and Space Administration (NASA). ${ }^{1}$ My past work reflects an interest in looking at biology from a cultural perspective and at culture from a biological perspective, with a particular interest in human evolution.

Human evolutionary theory and astrobiology share a similar feature. In both cases, central phenomena of scientific interest are elusive. Broadly speaking, for human evolution, it is life in distant pasts, conventionally, the PlioPleistocene. For astrobiology, it is hoped-for discoveries in the future, such as bacterial life beyond Earth, extraterrestrial intelligence, or habitable planets. One question is how do these two domains of investigation manage the "missing data" to sustain scientific work? Both are hybrids of science and culture sustained by a cushion of conventional science and public interests. However, they differ in a number of dimensions, which might be summarized as a difference between 20th-century and 21st-century science.

Let me say here that in some sense, all science is "hybrid," simply because it is undeniably "inside culture," even by the most shallow, albeit important measures (e.g., funding), but also by very deep, often tacit perceptual, cognitive, emotional, and situated phenomena that makes shared performance possible. I mean this article to be suggestive, not definitive, in hopes that future research might be inspired, especially on the relationship between culture and science, particularly in astrobiology. Thus the map of the article is quite simple, beginning with a brief

\footnotetext{
1 "Rethinking Life on Earth \& Beyond: Astrobiology and the Role of Paradigm Shifts in Science \& Human Self-Understanding," Blumberg Dialogues on Astrobiology, May 28, 2015. John W. Kluge Center, Library of Congress, Washington, D. C. https://www.loc.gov/today/ cyberlc/feature_wdesc.php?rec=6818.
} 
description of Latour's (1992) significant discussion of hybridity in science and culture, and then making a quick comparison of how human evolutionary theory and then astrobiology handled the "public interest side." The comparison is suggestive of how science as cultural practice has changed between the mid-20th century and the $21 \mathrm{st}$ century, possibly, oddly enough, for the better, by acknowledging the significance of science in culture and culture in science.

\section{Hybridity}

Science is a cultural practice, where imagination, craft, analysis, identity, expertise, and "rules of a game," come together around a set of shared concepts and activity. It is a particularly effective way of producing some forms of knowledge and harnessing it for the design and production of many-by no means, all—human artifacts and practices. It is not uncommon to call this "pure science," meaning that the research is conducted without concern for its value to society, which may (or may not) emerge later. ${ }^{2}$ In another time period, "pure science" carried a sense of being "untainted" by commercial, political, personal, or social interests. There was also a sense of science as "purely rational." These latter senses of purity have been contradicted by research in science and technology studies, and research in cognitive biases and heuristics (cf. Todd and Miller 2017, this issue). Importantly, what distinguishes science (but is not necessarily exclusive to science) is the rejection of supernatural causes, such as "intelligent design," and a commitment to data and logical analysis. At the boundaries of science, where some knowledge is to be extended into "the unknown," it's not even clear if the planned research will yield good results. Furthermore, serendipitous outcomes, those unforeseen when the research is planned, can occur, and those unanticipated outcomes can have important societal consequences. For completeness, we want to acknowledge that many experiments fail; nobody knows how great the number.

In We Have Never Been Modern, Latour (1992) hypothesized two sets of practices, purification and translation, which have remained effectively distinct in modern science. Purification includes the methods of "pure science" as well as those of deconstructionist humanities and social science analysis that are about science in culture. Billings (2012) is an excellent example of a sociological deconstruction of astrobiology and the search for extraterrestrial intelligence (SETI). For Latour, the science

\footnotetext{
2 In practice, many funding agencies require some consideration of "value to society," but often the values are more immediately felt in providing support for students.
}

domain draws boundaries around facts, nature, and artifacts, and the society domain encloses values, culture, and politics. Snow (1959) famously referred to these two practices of purification as "two cultures," an unfortunate choice of words leading to 50 years of binaries created by mutual "othering."

The other set of practices, translation, creates hybrids of science and society, facts and values, and nature and culture in a single public domain. Pick up any newspaper on any day, Latour advises, and we'll see hybrid science in play when we read a perfectly understandable story-just a single article-involving the problems measuring the ozone layer, CEOs of chemical manufacturing plants, pronouncements of government officials, and comments from consumers and protestors. We see in just one news story the interdependence among science, society, and culture. For the most part, these hybrids vanish when they are segmented and assigned to different academic disciplines; in the example of the news article, these include physics, chemistry, biology, manufacturing engineering, political science, economics, and psychology. Latour (1992) pointed out that purification and translation are necessary to each other. There would be no need for purification if science were truly detached from the needs, practices, and values of the social domain. Likewise, there would be no need for translation if humans did not value, need, and use science and technology. For Latour, like Snow (1959), the work of purification was incommensurable across the divide between science and the humanities and social sciences. Moreover, in some general sense, a balance had to be maintained between science and its social construction. Too much of social constructivist accounts of science makes one yearn to have more science realism. But what about the opposite?

\section{Origins}

Few areas of scientific study have been as fraught-historically, philosophically, scientifically, and socially-as that of human origins. Questions about origins and origin accounts are ubiquitous across human cultures; are posed by children themselves in early development; legitimize and privilege some social relations over others; and are flexibly altered to respond to changing social relations within and between generations. To study human origins is to be both agent and object of investigation. From the mid1970s through the early 2000s, sociobiology and later evolutionary psychology commanded more attention in the popular press than other approaches. Most of the translation-purification work concerned features purported to be genetically determined characteristics of human nature forged in the Pleistocene. As Buller's (2005) 
methodological critique of evolutionary psychology became widely known, evolutionary psychology approached its nadir.

Examples of what we can call hybrid science can be found in the work of Landau $(1984,1991)$ on the evolutionary scenarios of early 20th-century paleontologists. Superficially, their arguments may have turned on questions such as the priority of the evolution of tool use, moral sensibilities, or intelligence. However, they shared a deep narrative structure with traditional fairy tales such as Jack and the Beanstalk. In the evolutionary scenario, a primitive primate, forced to leave his tranquil home, must pass a series of tests aided by the gifts (intelligence, tools, etc.) of a donor (natural selection), is transformed into a human, and wins the prize of civilization-and its discontents. This structure is not limited to fairy tales; it is also evident in that iconic game of 20th-century baseball (Shore 1996). The batter leaves home plate, passes through the tests of reaching three bases with the aid of hits by his teammates, and if successful, returns triumphantly to home base. Paleoanthropologists quickly understood the problems of such narratives: they promoted a lineal view of human evolution, discounted the significance of other hominin taxa for understanding human evolution, and encouraged a tacit view of an animate nature "selecting" and "favoring" Homo sapiens as its ultimate achievement. One rarely sees such evolutionary scenarios in the professional literature of paleoanthropology any more.

Science and culture can be so comingled that scientists themselves are unaware of the mash-up. Billings (2012) documents the myriad ways in which the search for extraterrestrials, the epitome of elusive phenomena, has become "science" in astrobiology and at the same time serves as a cultural narrative responding to fundamental questions about "who, what, where, and why, we are" (p. 973). Her article for this issue (Linda Billings 2017) includes a telling example of comingling. She footnotes Francis Crick's use of the term "dogma" to apply to the idea in biology that the flow of genetic information proceeds from gene through various processes leading to the synthesis of proteins, but never in reverse. Dogma, suggesting unquestioning belief, and a term with significant religious associations, was a poor choice of terms. Oddly, it was invisible to Crick; he suggests he used the term as a synonym for "hypothesis," a term antithetical to dogma.

However, we can see dogma as a bellwether for a conceptual skeleton drawn from Christian religion. The genotype, like the soul, was considered the essence of the person; the phenotype, a "dead end" in evolution, was the vehicle of the genes, and paralleled the ephemeral body, vessel of the soul. Just as man had lost his place in the Garden of Eden, modern man has lost his natural environment. Dawkins' (1976) “immortal genes" paralleled original sin, and likewise could be resisted through the power of cultural memes. The metaphor worked well enough to scaffold an emerging science of genetics and eventually worked into accounts of origins including human origins.

There are some things that we can note about elusive phenomena. When important phenomena are vague, novel, or hard to test, it makes sense that emerging science draws from existing cultural frameworks to scaffold a language with which to express itself- "vine swinging," so to speak, from inchoate concepts of "something like" what the scientists wanted to say, albeit, not quite right. How else would scientists find ways to articulate for themselves and others things that they knew at best as "sort of like," or "not quite like" ways of communicating? ${ }^{3}$ As a concept, the gene was introduced and embraced in the 1920s. Its existence was inferred and assumed, but never observed. Importantly, having the concept, even if it was ephemeral, kept the science alive and productive (albeit with cultural costs; Darwinism was used in legitimating the eugenics movement and as a rationale for colonization in the 19th century and concentration camps in the 20th century). Later, various claims, such as "one gene, one trait" were made, but eventually did not stand up to the reality that appeared with better instrumentation, visualization techniques, and measurement. Today, the idea of genes as autonomous agents and units of inheritance is still used colloquially but is challenged scientifically. Portin and Wilkins (2017) propose a new definition of the gene that depends on phenotypic effects, but also requires evidence of a DNA sequence that specifies RNA/protein synthesis.

To sum up, the relationship of culture in science is not just one of societal impact. There are scientific consequences as well. In human evolutionary theory, cultural patterns can undermine and confound the identification and attribution of causes. At the least sophisticated level, this includes a series of familiar dualisms between nature and nurture, genes and environment, and biology and culture. However, notions that science lies outside culture, or is purely relative to culture, can blindside even the most dedicated of scientists. A hybrid science is thus problemcentered (as opposed to disciplinary-centered), reflexive, aware of the limitations of time and place, and alert to possible confounding assumptions and bias. A logic of research questions, and the research to which questions are connected, are still crucial (Lloyd 2015). (See Griesemer (2013) for a more general approach to hybridity that could be used to understand the evolution and development of science.)

\footnotetext{
${ }^{3}$ Stuart Newman (personal communication, 2018) has pointed out that artists face similar challenges. See the discussion by Prinz (2015) on Dürer's rhinoceros.
} 


\section{Astrobiology}

There are significant differences between research on human origins and astrobiology. Among other things, the latter is a program within NASA and hence has institutional support for a variety of agendas. These include biology projects on space missions, research on the early origins of life, catalyzing interdisciplinary research, and educational outreach, not only at graduate and postdoctoral levels, but also directed towards learners at all ages through educational programming and public outreach (such as the Blumberg/NASA event that sparked this collection of articles). The Planetary Society ("Co-founded by Sagan. Led by Nye. Powered by you." http://www.planetary.org) has about 50,000 members, space fans, as well as scientists and science celebrities, engaged in funding, advocating, and volunteering in political advocacy as well as universal educational outreach in support of space science. The "face," or rather "faces," of astrobiology are also different.

One of my earliest brushes with astrobiology was a TED talk by an astrobiologist who investigates climate on exoplanets to assess their habitability by modeling apparent contradictions in nature. Aomawa Shield remarks,

...it's no surprise that this is my specialty. I'm an African-American astronomer and a classically trained actor who loves to wear makeup and read fashion magazines, so I am uniquely positioned to appreciate contradictions in nature [laughter, applause] and how they can inform our search for the next planet where life exists. (https://www.ted.com/ speakers/aomawa_shields, 4:16)

While this personal attention to contradiction is partly aimed at young women who would never imagine that they could want or have a career in science, ${ }^{4}$ there is also a nervously understood message. If you can't deal with the contradictions represented by Shields, you may not be ready for encounters with extraterrestrial intelligence either.

Recall that Latour thought of purification and translation as two separate practices. They became momentarily hybrid in a newspaper story or wherever the public practice of translation could nail down purification. In some areas of research concerned with human origins, the intercalation of scientific facts and human values means they are so intertwined that "purification" does not occur. Some debate does take place in public and scholarly venues, as it did in

\footnotetext{
${ }^{4}$ Shields is also the founder and director of Rising Stargirls, an organization using theatre, writing, and art to engage middle-school girls from groups traditionally underrepresented in science in exploring and developing projects in astrobiology.
}

the early periods of sociobiology and later evolutionary psychology, but the same problems and issues are repeated (or ignored) and a stasis or boredom sets in. It is suggestive to consider three important intellectual bursts from the mid-1970s and later. In sociobiology, plate tectonics, and women's studies, we see different patterns. Plate tectonics was successfully incorporated into geology and broad views of the planet's history; women's studies changed culture and morphed into gender studies. Sociobiology gave rise to evolutionary psychology, but neither engulfed the human behavioral and cognitive sciences as Wilson (1975) initially imagined. Astrobiology does not seem to follow any of these patterns.

The Planetary Society, which also supports SETI, was founded in 1980. It was of considerable public interest, but hardly an "intellectual burst." The NASA Astrobiology Institute was an innovative approach organized almost 20 years later, in 1998, to develop the field by catalyzing and supporting interdisciplinary, national and international research teams, competitively selected for the integration of research and training. Both the foundation and the governmental institutional situation of astrobiology seemed to absorb "purification and translation" while enriching the science.

A small set of documents from 2006 to 2015 , two "astrobiology primers" and two NASA documents from the Astrobiology program, hint that the dimensions of science and society could be incorporated into a broader view of multidisciplinary, problem-centered astrobiological studies. The 2006 "Primer" v.1.0 (Mix et al. 2006) and 2008 "Roadmap" (Des Marais et al. 2008), made a nod toward the human dimensions of astrobiology indirectly in the context of contamination, from or to humans, and human missions. The concerns for planetary protection apparently were emergent in 2006, as the "Primer" notes it was too soon for protocols, which would be a matter of the science and instrumentation if and when possible life were discovered. By 2017, there was growing and shifting activity (https://planetaryprotection.nasa.gov/overview). Christopher McKay (2017) discusses the contamination question in this special issue. Although the first primer is somewhat rough, it has an exceptionally high level of graduate student input. This is significant because new entrants into a field cognitively organize information differently than experts. In an important sense, such primers can reach out more effectively to other students and nonscientists, including political actors.

The 2008 "Roadmap" goes a bit further. It lists seven goals and key domains for research. Two of these involved the search and evaluation of habitable planets. The other five concerned questions over different scales of time and distance about life: the recognition, presence, precursors, origins, evolution, and future of life on Earth and other 
planets, in term of physics, chemistry, biosciences, and geological sciences. For the purposes of this discussion, however, four basic principles that NASA's astrobiology program described as fundamental principles included just one item exclusively relevant to science: astrobiology would involve close coordination and cooperation among diverse scientific specialties. The other three fundamental principles pushed it into the realm of the hybrid: recognizing ethical issues associated with exploration, societal interests, and implications of astrobiological research, particularly the discovery of extraterrestrial life and "envisioning the future of life on Earth and in space," and the opportunity and necessity for educating "the next generation of scientists, technologists, and informed citizens."

The recent "Astrobiology Primer v2.0" (DomagalGoldman et al. 2016) and the NASA Astrobiology Strategy 2015 (Hays 2015) differ from the work in the previous decade. While both refer to the search for extraterrestrials, issues related to contamination, and multidisciplinary research, both are far more polished, have many more authors; and the evidence of diversity, including the number of women and participants from other countries, is notable. There is a new emphasis on the habitability of planets, including how astrobiology can contribute to understanding the continued habitability of our own planet, Earth. The NASA strategy document directly refers to the Anthropocene epoch (see James Malazita 2017, this issue), a concept underlying a multidisciplinary effort currently underway to recognize the new ability of humans to directly affect the planet on a global scale (e.g., geological evidence of a global layer of radioactive substances caused by bomb testing; Zalasiewicz et al. 2017). This includes understanding how human activity causes perturbations in the environment, the differences between reckless and wise civilizations in delaying or hastening the destruction of the biosphere of the planet as a whole, communicating knowledge of potential threats, and in a rare admission, the "challenging issues that the Earth Science community has had to confront - of ethics and the boundary between science communication and activism" (Hays 2015, p. 150).

At first glance, the last section of the last chapter (7.VI.) in the NASA Astrobiology Strategy 2015 appears to be concerned with the kinds of organizational issues that tend to plague most large institutions: communication, relationship building, and boundary negotiation for collaborative and interdisciplinary work. However, deeper and broader goals are acknowledged: astrobiology is also a scientific quest for answers to deep questions about human self-understanding. Therein lie opportunities and challenges for interdisciplinary collaboration with an "astrobiological humanities" community. In the manner of testing the temperature of the water with your toe, there is an appendix, in the structure and style of the preceding chapters, and named, "Beyond Natural Sciences: Humanities and Social Science Contributions to Astrobiology."

This issue of Biological Theory, representing a variety of interests, experience, and certainly of expertise, could be interpreted as-but isn't-a response to the appendix of NASA Astrobiology Strategy 2015. Instead, it is an emergent response to a topic, a series of events that are accidental in the larger scheme of things, including bits of cajoling, connections, scaffolding, and, if I may, goodwill. It is an indicator that astrobiology as hybrid science-reflexive, reflective, and responsive to the challenges of integrating different scholarly standards-is of interest in the humanities and social sciences, which potentially have important contributions to make to thinking in and about astrobiology.

Hybrid science is necessarily problem-centered. The problem - the missing observations, in particular-may require the usual (and sometimes painful) interdisciplinary work that occurs between disciplines specifically relevant to the problem. Some questions, in particular, "what is life?" may require a broader raft of disciplines and approaches. The articles by Carlos Mariscal and Leonore Fleming (2017) and by Kelly Smith (2018) (both, this issue) illustrate two different approaches that philosophy can offer, roughly, a positivist view of life more ordered along traditional science and a postpositive approach that acknowledges a certain messiness and resistance to order.

Future research on how humans actually attribute the concept of life might refine some of the questions and responses with respect to "what is life?" and "what is intelligent life?" here, including Peter Todd and Geoffrey Miller's (2017, this issue) article on "messaging to ETI," or METI. Humans are surprising in how variable they are in the attribution of human characteristics to animals, machinery, and natural objects, as well as how easily they can dehumanize other humans. Todd and Miller's approach to evolutionary psychology, which emphasizes the value of understanding cognitive heuristics rather than assuming rational optimality, may have more to contribute on this topic.

Both McKay's (2017, this issue) work, described above, on preventing contamination and Frans von der Dunk's (2017, this issue) work on space treaties also fall into the domain of hybrid science. The findings of scientific research, even if suggestive at best, set the stage for addressing the health and legal issues that come with discovering resources and even signs of life as part of exploration in our solar system. Von der Dunk's article describes changes in treaties relevant to exploration and exploitation of space over the last 60 years, as cultural actors change. Where the earliest treaties were limited to cooperation among nations for scientific exploration and were of interest largely to scientists and legal scholars, later treaties now must also consider relations 
among science and corporate actors along with nations and are of interest to space fans, volunteers, artists, and other players in popular culture.

\section{Hybrid Science for the Anthropocene}

Reading something in the press doesn't produce hybridity, so much as being a sign of hybridity. For the late 19th and much of the 20th century, science was considered "pure," "unbiased," beyond the reach of culture, politics, or greed. A scientist did his (rarely her) research. Science could be perverted or used for evil by others, but the rational scientist was above such human folly. These days, the 21 stcentury days of "grand challenges," are usually posed as a response to previous impetuous applications of science or technology. They require a different kind of science, focused on perspectives, processes, systems-thinking, and an acute awareness of how we distinguish, label, and track our phenomena of interest (Caporael et al. 2013).

There is a method to science, which, broadly described, is related to contrasting hypotheses and evidence to support or reject hypotheses. Some sciences are highly manipulable and carefully designed experiments can be undertaken; in other cases, experiments are precluded. There are observations and predictions about future observations and possibly changed conditions. The fundamental logic of science, that is, the interplay between hypothesis and evidence, need not be that much different from that in the humanities (cf. Barzun and Graf 1992). Collaborations between scientists, humanists, and social scientists as full partners (see Malazita 2017) can lead to good outcomes. For example, Mann et al. (2017), a climatologist, philosopher, and sociologist, worked together and recommend Bayesian approaches for climate change research because they could better serve both science and society.

It could be astrobiologists fail to find bacterial life, intelligent life, or habitable planets. However, beneath the surface of James Malazita's essay, I detect an infectious hope for the future. It is possible that we can master new, more reflective and participatory ways of doing science. What will matter is the quality of the quest: the questions we (and our "frenemies") pursue, the diversity and breadth of participation, and the new myths that we and our children construct for humanity, other species, and our relationship to our planet and the ones we contact.

Acknowledgements I am indebted to Joanne Luciano, Iain Bennett, Stuart Newman, Kelly Smith, and James Malazita for discussion and feedback, and to Colin Allen and Peter Todd for hosting me in the Cognitive Science Program, Indiana University. Robert H. Fakundiny, former chair of the North American Commission on Stratigraphic Nomenclature, generously explained the scientific issues involved in approval of the Anthropocene as a consensual scientific term. Deborah Klosky, managing editor of Biological Theory, provided exceptional support for the issue.

\section{References}

Barzun J, Graf HF (1992) The modern researcher, 5th edn. Harcourt Brace Jovanovich, New York

Billings L (2012) Astrobiology in culture: the search for extraterrestrial life as "science". Astrobiology 12(10):966-975. https://doi. org/10.1089/ast.2011.0788

Billings L (2017) From Earth to the universe: life, intelligence, and evolution. Biol Theory. https://doi.org/10.1007/s13752-0170266-6

Buller DJ (2005) Adapting minds: evolutionary psychology and the persistent quest for human nature. MIT Press, Cambridge

Caporael LR, Griesemer JR, Wimsatt WC (eds) (2013) Developing scaffolds in evolution, culture, and cognition. MIT Press, Cambridge

Dawkins R (1976) The selfish gene. Oxford University Press, New York

Des Marais DJ, Nuth JA 3rd, Allamandola LJ et al (2008) The NASA astrobiology roadmap. Astrobiology 8(4):715-730. https://doi. org/10.1089/ast.2008.0819

Domagal-Goldman SD, Wright KE, Adamala K et al (2016) The astrobiology primer v2.0. Astrobiology 16(8):561-653. https:// doi.org/10.1089/ast.2015.1460

Griesemer JR (2013) Reproduction and the scaffolded development of hybrids. In: Caporael LR, Griesemer JR, Wimsatt WC (eds) Developing scaffolds in evolution, culture, and cognition. MIT Press, Cambridge, pp 23-56

Hays L (ed) (2015) NASA Astrobiology Strategy 2015. National Aeronautics and Space Administration. https://nai.nasa.gov/ media/medialibrary/2016/04/

Landau M (1984) Human evolution as narrative. Am Sci 72:262-268

Landau M (1991) Narratives of human evolution. Yale University Press, New Haven

Latour B (1992) We have never been modern. Harvard University Press, Cambridge

Lloyd EA (2015) Adaptationism and the logic of research questions: how to think clearly about evolutionary causes. Biol Theory 10:343-362. https://doi.org/10.1007/s13752-015-0214-2

Malazita JW (2017) Astrobiology's cosmopolitics and the search for an origin myth for the Anthropocene. Biol Theory. https://doi. org/10.1007/s13752-017-0281-7

Mann ME, Lloyd EA, Oreskes N (2017) Assessing climate change impacts on extreme weather events: the case for an alternative (Bayesian) approach. Clim Change 144:131-142. doi:https://doi. org/10.1007/s10584-017-2048-3

Mariscal C, Fleming L (2017) Why we should care about universal biology. Biol Theory. https://doi.org/10.1007/s13752-017-02808

McKay CP (2017) The search on Mars for a second genesis of life in the solar system and the need for biologically reversible exploration. Biol Theory. https://doi.org/10.1007/s13752-0170284-4

Mix LJ, Armstrong JC, Mandell AM et al (2006) The astrobiology primer: an outline of general knowledge-version 1, 2006. Astrobiology 6(5):735-813

Portin P, Wilkins A (2017) The evolving definition of the term "gene". Genetics 205(4):1353-1364. https://doi.org/10.1534/ genetics.116.196956

Prinz J (2015) Dürer's rhinoceros: art, exotica, and empire. http:// www.artbouillon.com/2015/01/durers-rhinoceros-art-exoticaand-empire.html 
Shore B (1996) Culture in mind. Oxford University Press, New York Smith KC (2018) Life as adaptive capacity: bringing new life to an old debate. Biol Theory. https://doi.org/10.1007/s13752-017-0292-4

Snow CP (1959) The two cultures and the scientific revolution. Cambridge University Press, New York

Todd PM, Miller GF (2017) The evolutionary psychology of extraterrestrial intelligence: are there universal adaptations in search, aversion, and signaling? Biol Theory. https://doi.org/10. 1007/s13752-017-0290-6 von der Dunk FG (2017) Private property rights and the public interest in exploration of outer space. Biol Theory. https://doi. org/10.1007/s13752-017-0271-9

Wilson EO (1975) Sociobiology: the new synthesis. Harvard University Press, Cambridge

Zalasiewicz J, Waters CN, Summerhayes CP et al (2017) The Working Group on the Anthropocene: summary of evidence and interim recommendations. Anthropocene 19:55-60. https://doi. org/10.1016/j.ancene.2017.09.001 